\title{
Higher Education in Russia and Kazakhstan in Modern Condition
}

\author{
Nurbol Koyshybaevich Abishev \& Yessen Yklasovich Bidaibekov \\ Abai Kazakh National Pedagogical University, Kazakhstan
}

\author{
Victor Alekseevich Dalinger \& Oleg Victorovich Knyazyev \\ Omsk State Pedagogical University, Russia
}

\begin{abstract}
This article discusses changes happening in higher education systems of the Russian Federation and the Republic of Kazakhstan namely diversification, democratization, globalization and regionalization of education, as well as the main directions of modernization of these systems according to the Bologna Declaration: increased access to the European education, improving the quality of higher education, introducing comprehensible, comparable qualifications in higher education, introducing assessment of study attainment and performance in terms of credit points, inclusion of the curriculum in the diploma supplement, the increased mobility of students, teachers and administrative staff. The article also deals with the problems of higher education in the Russian Federation and the Republic of Kazakhstan, and analyzes competency-based approach to the construction of the educational process in higher education, and comments on the shortcomings of the competency-based approach. It also covers the basics of active and interactive learning technologies and methods for the diagnosis and assessment of learning outcomes (NPS - technology of assessment of the quality of learning outcomes, the system of expert assessments and the method of calculating Spearman's rank correlation coefficient).
\end{abstract}

Keywords: higher education, competency-based approach, NPS-technology of assessment of the quality of learning outcomes, the system of expert evaluations.

\section{Introduction}

Russia and Kazakhstan have been going through reforms in all spheres for the last decade, including higher education. Recent changes put forward innovative demands for higher education (Abitaeva, 2009; Zimniyaya, 2003; Motorina, Sokolova, 2013; On the framework of new model of public service of the Republic of Kazakhstan, 2011; Strategy Kazakhstan - 2050). Modern education models of Russia and Kazakhstan are based on the following principles: the openness of education to external inquiries; competitive identification and support of leaders who successfully implement the new approach; target-orientation of resource supportive tools; the complex nature of decisions, etc..

The higher education systems in both the countries are currently undergoing the following significant changes: 
- Diversification of education (changes in the content of education, changes of the educational values and so on.

- Democratization of education (Great openness of the world education);

- Globalization of education (linking of educational systems to integrated global educational networks);

- Regionalization (emphasis on special properties associated with the peculiarities of the development of the region within the global network).

\section{The systems of Higher Education of Russia and Kazakhstan in the Wake of the Bologna Declaration}

The Bologna Declaration was the step towards international cooperation in education and science. The Russian Federation joined the Bologna Process in September 2003; the Republic of Kazakhstan did the same in March 2010. The countries participating in the Bologna process are carrying out a set of measures for the harmonization of the education system, namely: adoption of a system of easily readable and comparable degrees promoting mobility of students, teachers and the administration staff; ensuring and improving the quality of education through the introduction of common methodologies and criteria; establishment of system of credits to unify the system of counting volume of academic work; cooperation of universities in Europe to guarantee the quality of education; lifelong learning; increasing the degree of autonomy of universities and so on.

Modernization of the system of Russian education and the education system of the Republic of Kazakhstan according to the requirements of the Bologna Declaration includes the following measures:

- increasing access to European education, further improving quality of Russian education;

- Adoption of a system of easily readable and comparable degrees;

- Establishment of assessment of study attainment and performance of students (courses, programs and load) in terms of points (c

- redits);

- inclusion of the curriculum in to the diploma supplement, the model of which was developed by UNESCO;

- increasing mobility of students, teachers and administrative staff;

- ensuring the required quality of higher education;

- introduction of postgraduate education in the general system of higher education (as a third level);

- giving the "European dimension" to the higher education and increasing the competitiveness of European education;

- ensuring the autonomy of universities;

- adoption of new state educational standards of higher education by universities;

- implementation of competency-based approach and others in the educational process.

Now the Russian and Kazakhstani systems of higher education are being replaced by a new multilevel systems which significantly differ from one-level one both in content and structure. 
Under the new multi-level training formula a person may spend 4 years on obtaining graduate bachelor's degree and two years on mastering special knowledge and professional skills (Master's degree).

There are different viewpoints of scientists, educators and public figures on the ongoing education reforms.

A. V. Shevkin notes that "we are reforming and reforming the education, and it still is not reformed. Brest Fortress of Russian education is not to give up. Reformers' last resort is to cut off the influx of combat-ready forces to it, to degrade the system of fundamental training of future teachers, making a focus on dismissal of activity-based and competency-based approaches as well as on internship at school"(Shevkin, 2004).

According to the ongoing reforms we should make an emphasis on the educational services provided by educational institutions.

As for the "system of educational services", Patriarch Kirill criticized them in his speech before the students of Voronezh State University: "Today education is exclusively recognized as a commodity service. It is as strange as if we gave citizens the right to recruit soldiers and acquire military equipment for their personal money if they wanted to... Education is not a private matter of people, it is rather a sphere of public life which determines the existence of society and the state. It is the backbone of the society's existence and, therefore, turning of education exclusively into the sphere of market services is a big mistake ... "(Patriarch Kirill, 2011).

International cooperation in education and science is an objective necessity of modern education all over the world. One of the trends of the Russian and Kazakhstani education systems is their integration into the world educational space: the transition to multi-level education system, integration of means of monitoring the quality of education and others.

The vacuum of values in education, the ideological vacuum in the society, mental incompatibility of individuals and communities are serious problems nowadays. That is why, formation of ideological and mental priorities of the individual becomes the main vector of activities of educational institutions in the modern world.

Modern trends outlined in the Russian Federal Law "On Education" and the regulatory documents of the Republic of Kazakhstan, explain the principles of the state policy in the field of education: humanistic nature of education; priority of universal values, human life and health; the free development of individuals; the protection of education systems of national cultures in the multi-ethnic states; universal access to education; freedom and pluralism in education and others.

According to the framework of modernization of education the main task of educational policy is to provide education of modern quality based on the preservation of its fundamental nature and its correspondence to current and future needs of individuals, society and state.

According to the new ideology, education in general is not reduced, as before, to the level of imparting and acquiring knowledge and skills. Education today must ensure that learners master the social experience through which they form individual experience in solving cognitive personal problems. This will enable learners to achieve a certain level of education: awareness, literacy, functional skillfulness, competency. 


\section{University admission practices}

Analysis of data on applicants' admission to universities for several years shows an increasing number of those who apply to multiple programs after leaving school. This situation reveals the fact that career guidance should change its character. Probably it has to be continued in the walls of the university which an undergraduate entered.

Practice shows that more self-confident applicants, as a rule, are limited to applying to one program whereas less prepared applicants apply for 3-4 programs, and even more.

The combination of fields of study at the stage of admission to universities suggests, rather, applicants' professional uncertainty and indifference to the process of selection. In this case, the main purpose is, apparently, just entering the university for a diploma.

In 2012, Omsk State Pedagogical University conducted a sociological survey among students. Answering the question "What did you take into consideration while choosing your program?" $27 \%$ students responded "I failed to be admitted to another program", "the university is next to my house," "it happened by chance."

Analyzing the documents of 2013 Omsk State Teacher Training University Admission board, we found out that, in general, only 50\% of applicants get enrolled according to their first priority, and this percentage varies from 83\% at Department of Art to 31\% at Department of Mathematics, Computer Science, Physics and Technology.

For some programs, the situation is even more catastrophic: Physics and Technology - 5\%; Computer Science and Technology - 8\%; Cultural Studies - 14\%; Chemistry and Health and safety - o\%. Only three programs: Applied Computer Science, Economics and Management, Music Education have good results in terms of admission according to the first choice - $100 \%$.

The analysis shows that the most important factors at the core of the decision to enter the university are the motive of value of higher education as such ("desire to obtain a diploma of higher education" (44.8\%) and "the desire to receive higher income later" (44\%)). Such motive for higher education as the desire to acquire a profession was noted only by one in three respondents (31.9\%), the opportunity to acquire knowledge is significant only for $16.6 \%$ of the students.

According to statistics, in the mid 1990 from $40 \%$ to $60 \%$ of graduates were employed with no connection to their diplomas and had to improve their qualifications or retrain. At present, $51 \%$ of graduates would like to get a second degree.

This situation is typical for both Russia and Kazakhstan.

\section{Higher Education and Competency-based Approach}

Russian and Kazakhstani higher education systems currently implement the competency-based approach. The basic concepts of this approach are the "competency", "competence", "professional competence".

In Russia, Kazakhstan, as well as in the US, there is no single definition of "competency", which would include all the features of this construct. Indeed, in one case, competency is a statement of purposes, in another case - a skill. Knowledge and skills are also seen as kinds of competencies. 
In the NPEC report (National Postsecondary Education Cooperative) analyzing initiatives on introducing competency-based approach to the US education, the competency is defined as a blend of skills, abilities and knowledge needed to perform a specific task in a given context.

Competency-based approach is a set of common principles determining the aims of education, selection of the content of education, organization of educational process and evaluation of educational outcomes (Abitaeva, 2009; Dalinger, 2012; Bidaibekov,2014; Dalinger, Abishev, 2015; Zimniyaya, 2003; Plotnikova, 2008).

Under the competency we understand the quality of the individual, manifested in activities based on knowledge and experience. Competency of a student is the ability to solve various problems in everyday professional and social life by means of knowledge, abilities and skills acquired during training (ability is not understood as predisposition, but as a skill - "can do").

Competency is the ability to act in a situation of uncertainty.

The ability to solve problems is not limited to the development of a certain set of skills. This ability has several components: Motives of activities; ability to navigate among the sources of information; skills needed to perform certain activities; theoretical and practical knowledge necessary for understanding the problem and choosing ways to solve it.

Competency is the readiness (ability) of the student to use the acquired knowledge, training and skills, and modes of activity in his/her life to solve practical and theoretical problems.

The key educational competencies are:

1. Value and meaning-oriented.

2. General culture-oriented.

3. Educational and cognitive.

4. Information.

5. Communicative

6. Social and working.

7. Personal (self-improvement).

In addition to the core competencies that are common to all subject areas, subject competencies are isolated and they are the specific skills necessary for the effective performance of a particular action in a particular domain and include highly specialized knowledge, a special kind of subject skills, habits and ways of thinking.

In particular, mathematical competency is the ability to structure data (situation), isolate mathematical relationships, create a mathematical model of the situation, analyze and transform it, interpret the results. In other words, the mathematical competency of the student contributes to the adequate application of mathematics to solving emerging problems in everyday life.

The set of competencies, the availability of knowledge and experience required to operate effectively in a given subject area are called competency. Competency is evident in the case of applying knowledge and skills in solving problems, other than those in which the knowledge is acquired. The competency of an individual in a particular field is determined by the level of her achievements in this field.

At present, in the international research three levels of mathematical competency are universally accepted: the level of reproduction, the level of establishing connections, the level of reasoning. 
The first level (level of reproduction) is a direct application of known facts, standard procedures, recognition of mathematical objects and properties in a familiar situation, implementation of standard operating procedures, use of known algorithms and technical skills, work with standard, familiar expressions and formulas, direct calculations.

The second level (level of establishing connections) is based on the reproductive activity of solving problems, which, are not typical, but still familiar to students or go beyond the wellknown things only to a very small degree.

The third level (level of reasoning) is perceived as development of the previous level. To meet the challenges of this level one needs a certain intuition, reasoning and creativity in her choice of mathematical tools, the integration of the different branches of mathematics, independent development of the algorithm of actions.

These levels of mathematical competency are mainly manifested in solving mathematical problems, corresponding to three levels of complexity, taken in the development of test materials in mathematics within the framework of Unified State Exam: basic, enhanced, and high.

Tasks for checking mathematical competency can be of two types: the purely mathematical and the contextual (practice-oriented).

Current textbooks for students, including mathematics ones, are written in accordance with knowledge paradigm of education, which largely prevents the formation of students' competencies and expertise.

The new law "On Education of the Russian Federation" gets priorities straight, defining education as "... a set of acquired knowledge, ability, skills, system of values, experience, and competency of a certain size and complexity ...”.

Reading this interpretation in which knowledge, skills, and competencies are on the list separated by commas, one can get impression that knowledge and skills are not included in competencies, and that of course is nonsense.

V. S. Senashenko said: "Attempt to adapt the "competency-based approach" lying at the heart of Federal State Educational Standards of Higher Professional Education (FSES HPE) to solving the educational problems of higher school is not the only problem ... The gravity of current situation is the fact that universities will try to increase the volume of activities not typical for institutions of higher education, at the expense of solving their main task - training specialists with university education of high quality, realizing the necessity for professional maneuver in their future activities "(Senashenko, 2014). He continues: "As a result of the introduction of FSES HPE based on" competency-based approach", and more precisely on "eclectic model" of specialists, universities immerse in simulation mode of rather strange education-associated activities ... The Federal Service for Supervision in Education and Science of RF pretends that owns the evaluation tools for these competencies and issues verdicts on the effectiveness of institutions of higher education. And as a result, on the level of the education system, some "educational phantom" is being formed having unpredictable consequences for the quality of graduates' higher education "(Senashenko 2014).

Some "new" - "eclectic model" is actually proposed and used, which can be called neither knowledge-based nor competency-based model of a specialist. They should not have started the whole thing of giving this innovation for the competency-based approach (Lyle, Spencer, 2005), keeping on toes the whole system of national higher education and paying extra attention to it. 
New educational standards require emphasis on students' self-guided work, which entails a different method of organizing lectures and practical classes. In this regard, lectures are increasingly acquiring review character and practical classes resemble seminars.

If competency-based approach is applied to designing and implementation of FSES, various activities serve as the backbone elements of educational process; the subject of education takes active position and the activity is the basis, the means and conditions of individual development. This aspect is fundamentally changing the model of interaction between teacher and student.

In the traditional approach, which implemented knowledge and subjects-oriented paradigm of education, the aim was to equip students with the knowledge, skills and abilities; methods of communication were limited to counseling, explanation, prohibition, threats, punishments, reprimands; strategy was based on dictation and care; the position of teachers was reduced to implementing curriculum, meeting the requirements of the management and supervisory bodies; they lived according to the slogan: "Do as I do!" and so on.

In competency-based approach, the goal is to form personality, to develop individuals, to facilitate the development of the personality (knowledge and skills are not the goal but rather the means for development); ways of communicating are reduced to understanding, recognition and acceptance of individual, to taking into account the students' points of view and their feelings and emotions; strategy is based on the ideas of co-operation; the position of the teacher is based on students' interests and prospects of their development; teaching staff work in accordance with principle: "not side by side or above, but rather together!" The student is a full partner.

\section{Higher education and training technology}

The effectiveness of the implementation of competency-based approach in education depends on the active and interactive learning technologies, including information and communication ones.

There are bachelors and masters educational programs in Data Science (Data mining), as well as PhD level programs in these and related areas in the foreign universities (doctoral Institute, 2011). Data science aims to detect patterns in the data and extract knowledge from either structured and or unstructured data (Vasant, 2013). The process of rapid accumulation of digital data is taking place- the volume of accumulated digital data grows by about $50 \%$ every year (James Manyika et, al). Digital tools have to become leading means of teaching students.

The capabilities of computer technology as a tool of human activity led to the emergence of new teaching methods and organizational forms that are rapidly being introduced in the educational process. Information and communication technologies can significantly increase visualization of teaching, implement a model of individual-oriented education, facilitate assessment of students' knowledge, improve their cognitive activity, accelerate the pace of learning, intensify the process of learning.

There are educational environments and computer tutorials among teaching tools. Educational environment allows students to develop creative skills by establishing favorable environment, exploring which students obtain the necessary knowledge. Computer tutorials provide demonstration of educational material, training in a specific area, testing and diagnostics to monitor the training. 


\section{Education quality assessment tools}

Education quality assessment tools are of great importance within competency-based approach. Fill-in tests, online tests for students as integral parts of the accreditation procedure implemented by the university check students' knowledge but not their competency. It is time to review the tools used to measure the results of implementation of higher education programs (The Chronicle of Higher Education, 2013).

Let us consider the use of NPS-technology for evaluating the quality of learning outcomes. NPS (Net Promoter Score) is currently one of the key tools to measure customer loyalty in many client-oriented institutions (insurance companies, banks, and so on.). The notion of Net Promoter Score (NPS) was first introduced by Reichheld (Reicheld, 2006).

NPS-approach by Reichheld has the following shortcomings: : too rigid rating scale of responses and great sensitivity to insignificant changes in the parameters of survey, the lack of a rigorous mathematical framework to validate the findings.

In Malygina's paper (Malygina, 2009) a new concept of generalized Net Promoter Score with a more flexible scale compared with Reichheld's scale is introduced. The probabilistic model of NPS-approach to assessment of quality of a certain class of structures has been built.

O. A. Malygina analysed the dynamics of NPS based on the theory of the selection of the final general totality and limitary technologies.

It is advisable to introduce this material as a section of course on theory of probability. In the process of studying this material the students form mathematical competency as well as a number of professional ones. Having studied generalized NPS and its properties, students are able to build a variety of practically important models; their analysis, on the one hand, requires the use of standard methods of the theory of probability, and on the other hand, shows the features of final general totality, allowing to build compromise evaluations of generalized NPS based on using the theory of credibility.

Currently, compromise assessment of NPS is based on the use of credibility theory (Herzog, 1999), which enables to acquire an assessment of the generalized NPS for subsystems. At present, project-based training is widely used in higher education. Results of learning projects obtained by students are submitted in the form of an individual presentations, reports, collective presentations, and so on. It is very important how the results will be evaluated. The system of expert evaluation is one of effective assessment ways of learning outcomes. An objective assessment of knowledge and skills is necessary condition for the pedagogical process. Participants of various forums and contests express the opinion that expert evaluations differ. What measure should one choose to organize coordinated work of several experts? Forming a committee of experts for the evaluation of results of a competition or presentations we should have a criterion for comparing the consistency of assessments of the commission members (the jury).

In our study (Dalinger, Sovertkov, 2009) we propose a method for comparing assessments made by three experts. It provides mathematical basis for obtaining Spearman's rank correlation coefficient. 


\section{Graduates of higher educational institutions and the labor market}

University graduates do not always meet the requirements of employers. According to them, the graduates often do not have adequate training to work successfully. Currently there is a gap between the education system and the needs of the labor market. In general form, the essence of the claims of employers to higher education can be expressed as: university graduates receive superficial knowledge, far from the needs of practice; the quality of training does not allow higher school graduates to adapt quickly to the new professional environment. More than $50 \%$ of employers are not satisfied with the modern training in higher education institutions.

We can note that the transition to system with bachelor degrees, this dissatisfaction increases. Scientists note that currently only $10 \%$ of the most talented and diligent students receive the quality of knowledge that is required today. The national economy gets only about 8o85 thousand graduates of Russian universities, who are highly qualified professionals, meeting the requirements of the first quarter of the 21st century.

Currently, there is inconsistency between theory-based concept of providing only professionally oriented higher education by bachelor programs and actively promoted paradigm of providing higher professional education by bachelor programs.

As for bachelor programs in European countries, it is appropriate to compare them with the educational programs of Russian technical schools and colleges. Comparing Russian and Western European educational programs, one may notice that the most important properties of higher education in Russia are its fundamental nature, scientific character and excessiveness of subject content with respect to the particular type of professional activity of graduates, while universities in Western Europe focus on the development of practical skills. Fundamental nature of education is one of the main advantages of higher education in Russia.

We should note that bachelor degree does not make a person a fully-fledged professional. There are two views on bachelor degree: Bachelor is a trained professional, but still someone who received deficient education compared with specialist training; Bachelor degree is higher, but not professional education; it is rather only profession-oriented education. It should be noted that the removal of professional training from bachelor programs transforms university education into for the most part into "general education."

The transition of universities in Russia and Kazakhstan to the multi-level education system dramatically changed the approach to the ratio of hours on studying various disciplines. Let us confirm the above stated ideas with the following facts.

Compared to specialist degree, the number of hours on subject training in bachelor degree is drastically reduced. For example, more than 50 years ago (1963) the curriculum of Mathematics Department of Gorky Omsk State Teacher Training Institute defined that Mathematical analysis was taught for 1000 classroom hours; and at present (2015) at the Department of Mathematics, Computer Science, Physics and Technology at Omsk State Pedagogical University the same discipline is taught for 540 hours, out of which only 234 hours are classroom hours; If the course "Additional branches of mathematical analysis" 50 years ago was taught for 192 classroom hours, now it takes only 108 hours, out of which 26 hours are classroom hours. In 1963, the course "Elementary Mathematics" at Mathematics Department was taught for 640 classroom hours whereas in 2015 the same course is taught only for 360 hours (this is the whole length out of which 162 hours are classroom hours). This situation is universal. 
Today, a sharp reduction in the number of hours on the mathematical disciplines at bachelor programs leads to the situation when students form neither knowledge, abilities and skills on the subject nor competencies proclaimed by modern standards. Students neither assimilate theoretical knowledge, nor acquire the ability to solve mathematical problems.

If we are to continue training according to the existing curricula of Bachelor programs, there is an urgent need to find effective ways and means of improving the quality of mathematical instruction to students. The question arises on what can be done in these circumstances.

\section{Conclusion}

The principal directions of improving (or more accurately saving) of mathematical education are as follows: dismissal of two-level (bachelor and master) system of training teachers of mathematics and the return to specialist degrees for training mathematics teachers (medical universities managed to defend their right to train medical personnel through specialist degree programs); change of trend towards sharp reduction in the number of hours on training teachers of mathematics in corresponding subjects and teaching techniques .

Analysis of 44.03.03.05 "Teacher Training" bachelor program of Federal state educational standards of higher professional education shows that the standards lack subject component.

The standards do not mention the fact that subject teachers should know their subject at least within the school course. It is noteworthy that the new Russian Federal state educational standards 3 +among competencies to be checked at state final examination, there is not a single competency which would have checked graduates' subject knowledge. Subject training should be at the heart of training bachelors.

Prospects for further research on the subject studied in the article might be as follows:

1) Development of innovative technologies, didactic means of providing more effective formation and development of competencies and competence in students.

2) Didactic refinement of used textbooks for students aimed at bringing their content into compliance with requirements of the competence-based approach.

3) Development and implementation of diagnostic tools which monitor the degree of maturity of competencies and competence on academic subjects in university students. .

4) University work on recruiting prospective students oriented at this particular university specialization.

As a conclusion we would like to cite Pyotr Chaadaev: "To form special attitude towards educational issue in Russia, national foundation can be given to it; this national foundation is completely different from one on which education is based in the rest of Europe, because Russia developed in all respects in a different way, special destiny fell to its lot in this world".

\section{References}

Abitaeva, R.Sh. (2009). Competency-based approach in the preparation process of School Masters. (4, 52-55). Professional Kazakhstan.

His Holiness Patriarch Kirill's Speech at Voronezh State University 18.09.2011

Dalinger, V. A. (2012). Federal state educational standard of the new generation and systematic activityoriented approach to teaching mathematics. (6 (1), 19-22). Fundamental Research. 
Bidaibekov, Y.Y. (2014). Matematika men informatika boyynsha bilim beru magistrleri men PhD doktorlaryn dayyndau khakynda (in Kazakh). (3 (47), 70-75). Bulletin of Kazakh national pedagogical university named after Abai. Series of Physics and Mathematics sciences. Almaty.

Dalinger, V. A. and N. K., Abishev. (2015). Activity-based approach to profession-oriented training of bachelors of Mathematics (Education) theory of analytic functions. (2 (10), 2239-2242). Fundamental Studies.

Dalinger, V. A. and P. I., Sovertkov. (2009). A Method to Determine the Extent of Consistency of Expert Evaluations. (8, 44-50). Mathematics and Computer Science and Education: Interuniversity Collection of Scientific Papers. Yearbook. Omsk University Press.

Zimniyaya, I. A. (2003). Key Competencies - a New Paradigm of Education Outcomes. (5, 36-45). Higher education today.

Malygina, O. A. (2009). NPS-technology for Quality Evaluation in Education. (2, 111-115). Higher education in Russia. Moscow.

Motorina, O. P. and O. A. Sokolova. (2013). Content of education on the basis of competency-based approach. $(1,61-71)$. Innovations in education.

Plotnikova, N. A. (2008). Essence of the Competency-based Approach. Key Competencies. (2, 164-172). Bulletin of the Kazakh-American Free University.

Senashenko, V. S. (2014). Competency-based Approach in Higher Education: Myth or Reality. Proceedings of the international scientific conference "Education, Science and Economics in Universities and Schools. (54-61). Integration into the international educational space Tsehnadzor (Armenia).

The Chronicle of Higher Education. http://chronicle.com/section/Home/5.

James, Manyika et al. Big data: The next frontier for innovation, competition and productivity. McKinsey Global

Lyle, M., J.R., Spencer and Signe M. Spencer. (2005). Competency at work. Models for Superior Perfrormance. (384). Johu Wiley \& Sons, Inc.

Herzog, T. N. (1999). Introduction to credibility. Third Edition.

Reicheld, F. (2006). Ultimate Question: Driving Good Profits and True Growth. Harvard Business School Press.

Vasant Dhar Data science and prediction. Communications of the ACM. (2013). Volume 56 Issue.

Institute, 2011. http://www.listudy/com/list/data-science/university-doctoral

On the concept of a new model of public service of the Republic of Kazakhstan: Decree of the President of the Republic of Kazakhstan dated July 21, 2011 № 119. http://www.akorda.kz

Strategy Kazakhstan - 2050. New political course of the successful state: Address of the President of the Republic of Kazakhstan Nursultan Nazarbayev to the people of Kazakhstan. December 14, 2012. http://www.akorda.kz 